\title{
Effect of Air Supply Mode on Indoor Air Quality Using Fresh Air System
}

\author{
Zhen Gao ${ }^{1,3}$, Qiang Wang ${ }^{3}$, Haowei Hu ${ }^{2,3, a}$, Guotao Zhu ${ }^{2,3}$, Bingzhan Ren ${ }^{1,3}$, Siwei Zhang ${ }^{1,3}$ \\ ${ }^{1}$ Chinese Hefei Railway Constrction Real Estate Group C.O.. Ltd, Hefei 230041, China \\ ${ }^{2}$ College of Environment and Energy Engineering, Anhui Jianzhu University, Hefei 230601, China \\ ${ }^{3}$ Anhui Advanced Technology Research Institute of Green Building, Anhui Jianzhu University, Hefei 230601, China
}

\begin{abstract}
The different ways of fresh air into the indoor, different forms of organization, will affect the indoor comfort. Meanwhile, it can affect the quality of indoor air. The test of the fresh air system mainly involves the indoor temperature and humidity with and without return air. Based on various air organization conditions, the best scheme is put forward. In this work, the influence of the air inlet location on the indoor air quality is studied, and the indoor thermal environment of the room is optimized under the condition of the fresh air supplied.
\end{abstract}

\section{Introduction}

In recent years, the rapid development of China economy has made the air environment deteriorated, such as greenhouse effect, vehicle exhaust, haze and so on[1]. The traditional way of fresh air treatment has been unable to meet the requirements for air quality. Along with this process, a large number of buildings have been built. Improvement of indoor air quality and protection of human health are important goals for contemporary architectural environment[2]. Indoor air distribution and quality is important for architectural environments. It has been reported that the over-standard rate of formaldehyde and TVOC in underground buildings has reached $66.7 \%$ and $77.8 \%$ respectively [3]. Emissions of formaldehyde and total volatile organic compounds (TVOC) are influenced by many environment factors[47], such as temperature, humidity, air velocity and merchandise materials. The simulation based on the CFD software to the air flow pattern under three different types of air distribution (up-inlet and up-outlet, downinlet and up-outlet, up-inlet and down-outlet) when the office buildings adopt the dry fan coil units and dedicated outdoor air system, is used to analyze the impact of different air distribution on air flow pattern through the study of indoor temperature field and velocity field in the summer case[8]. How to improve the new air treatment scheme, improve the quality of indoor air and ensure the health of indoor is a new topic and new challenge.

To investigate the effect of air supply mode on indoor air quality, indoor fresh air quantity is first obtained, and it is a key factor for indoor air quality. Fresh air can help wipe off indoor pollutants, which is diluted to the allowed range. To control the indoor thermal environment effectively, furthermore, the return fan is being added to acquire the formation of organized exhaust. However, there are less quantitative researches on the effects of fresh air on the improvement of the thermal environment so far.

The test of the fresh air system mainly involves the indoor temperature and humidity with and without return air. Based on various air organization conditions, the best scheme is put forward. In this work, the influence of the air inlet location on the indoor air quality is studied, and the indoor thermal environment of the room is optimized under the condition of the fresh air supplied.

\section{Experimental instruments}

During the test of indoor air temperature and humidity, two additional exhaust fans have been added. In the experimental investigation, the main instruments involve the exhaust devices, the air supply devices, the temperature and humidity sensors, the air speed measuring instrument and indoor air quality analyzer. Their typical parameters and working principle are described as follows. Air exhaust design: adding air exhausting machine, total two. The air inlet is corresponding to the two new wind inlets, and the rated air volume is $135 \mathrm{~m} 3 / \mathrm{h}$, the wind can be adjusted. The location opposites to the air inlet, that is, the distance between the two exhaust fans and the two air outlets is equal to the west wall of the negotiation room, which is close to the ceiling of the north glass curtain wall. Air supply design: the air supply valve is configured for each air vent, and the air volume is linear and adjustable. The valve diameter should match the diameter of the existing supply branch pipe. A total of six temperature and humidity recorders were set up to measure the indoor heat and humidity environment in real time. The precision of air speed measurement instrument is within $0.1 \mathrm{~m} / \mathrm{s}$. the distribution of indoor air speed can be tested.

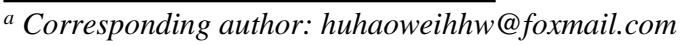


During the experiment, PM2.5 testing instruments are used to measure and analyze the indoor air quality.

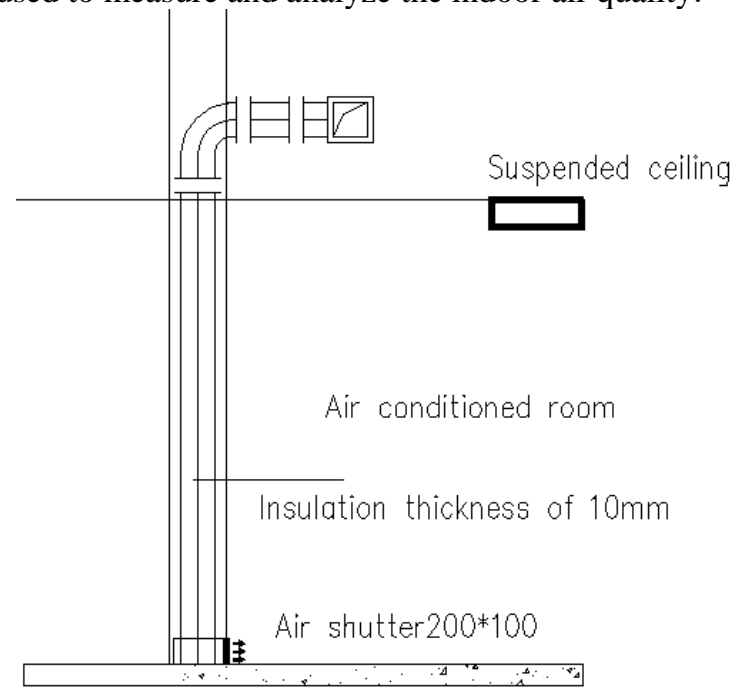

Figure 1. Schematic diagram of indoor test system

\section{Test method}

The test method of indoor and outdoor temperature and humidity is described as followed. As shown in Figure 1, two blowers are equipped in the system. And they are related to two supplied outlets of fresh air respectively. The rated volume flow of fresh air has been mentioned in the above section. Its volume flow can be adjusted. The experimental test contents of fresh air system are the indoor temperature and humidity under the conditions of different seasons with and without return air. During the debugging period, six sets of indoor temperature and humidity measuring instrument are placed in three different locations, as shown in Figure 2. And two of the same type of equipment in one position is set in different heights, which are away from the floor $1 \mathrm{~m}$ and $2 \mathrm{~m}$, respectively. Their numbers can also be shown in Figure 2 According to the requirement of external temperature conditions, the operation was carried out in the coldest and hottest month. Therefore, in our work, the winter and summer were selected, and each phase test kept for two weeks. Apparatus in different places included six sets of indoor temperature and humidity testing instrument, two of the same plane position instrument settings in different heights. The distances between the apparatus and floor were $1 \mathrm{~m}$ and $2 \mathrm{~m}$, respectively. And an outdoor temperature and humidity meter was decorated on the outdoors wall of the testing room. Two weeks of each phase testing time specific arrangement was as followed. The one was that testing indoor and outdoor temperature and humidity conditions in the case of indoor fan back closure in the measurement of the first week. The other was the testing indoor and outdoor temperature and humidity in the case of open the indoor fan back in the first week.

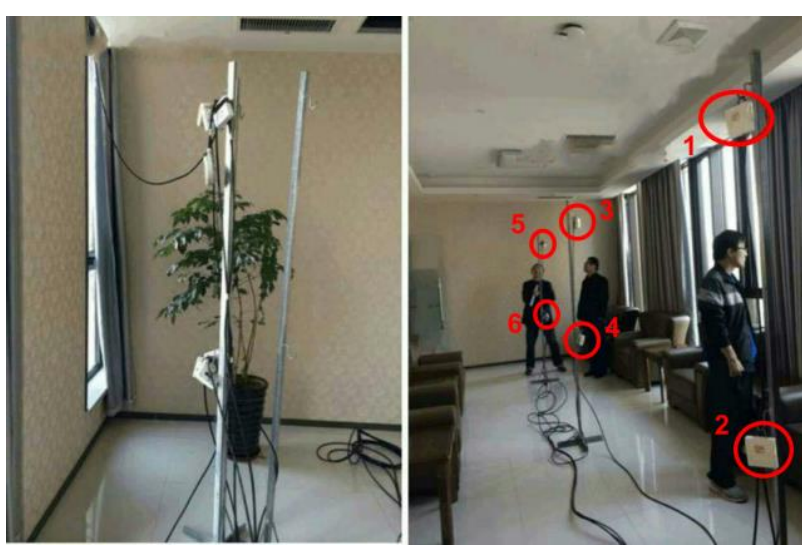

Figure 2. Actual locations of experimental test

All data transmission interfaces are collected in the control box of the 3 building pipe well, and the data output port is set up, which can be connected out of electricity.Brain or wireless monitoring system data. In addition, the system data can be everywhere in the form of EXCEL, and is convenient for further analysis.

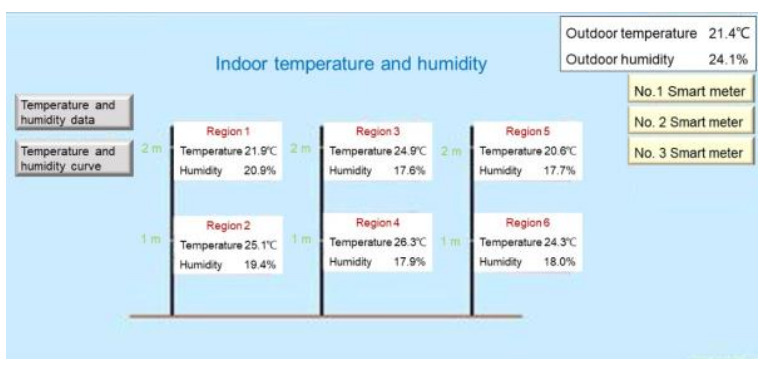

Figure 3. Display interface of test data acquisition

\section{Results and discussion}

Figure 4 and Figure 5 show the temperature and humidity distribution of region from 1 to 6 during a typical day. Through the analysis on the test results, four main factors affecting the thermal comfort of the human body are the type of air supply outlet, the distance from the air outlet to the human body, the velocity and temperature of the air supply. Therefore, according to the importance of factors and the best comfort requirements, the design of air flow organization can be optimized. The task of air organization is to reasonably organize indoor air flow distribution, so that indoor air temperature, humidity, speed and concentration can observably meet the process requirements and the health requirements and comfort requirements of human body and save energy as much as possible. The four main factors that influence the comfort of the down draft air low organization are: the distance between the air inlet and the body, the temperature of the air supply, the speed of the air supply and the type of the air inlet. The influence of air inlet type is much smaller than that of the other factors, thus, the air inlet type can be ignored, and the relationship between the skin temperature difference and other factors is as follows.

$$
\Delta t_{s k}=a-b s+c v_{s}-0.24 t_{s}
$$


where, $\Delta$ tsk is the temperature drop of human skin, which refers to temperature difference between chest temperature and foot temperature. It is an important index to measure the thermal comfort of human. Due to the particularity of air conditioning in thermal comfort (such as, air flow sense, vertical temperature gradient, and so on), physical reaction is mainly reflected in the skin temperature difference. Therefore, lower numbers equate to better performance. The general requirement of this temperature different is within $3{ }^{\circ} \mathrm{C}$. $\mathrm{s}$ is the distance from the air outlet to the human body, vs is the air flow velocity, and ts is the air supply temperature. $a, b$ and $c$ are constants with different values based on different conditions. In this work, values of $\mathrm{a}, \mathrm{b}$ and $\mathrm{c}$ are 8.42, 2.07 and 0.83 , respectively. For the air outlet, the new model patents can be developed to solve the optimization problem of air flow organization.

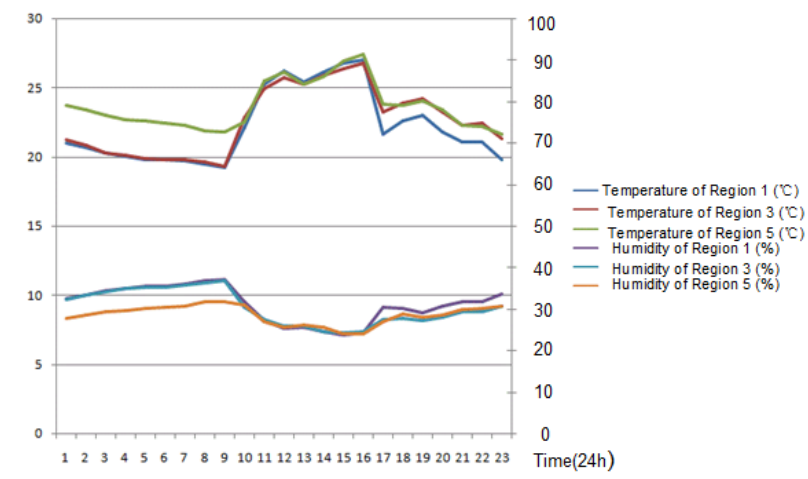

Figure 4. Temperature and moisture distribution of region 1, 3 and 5 during a typical day

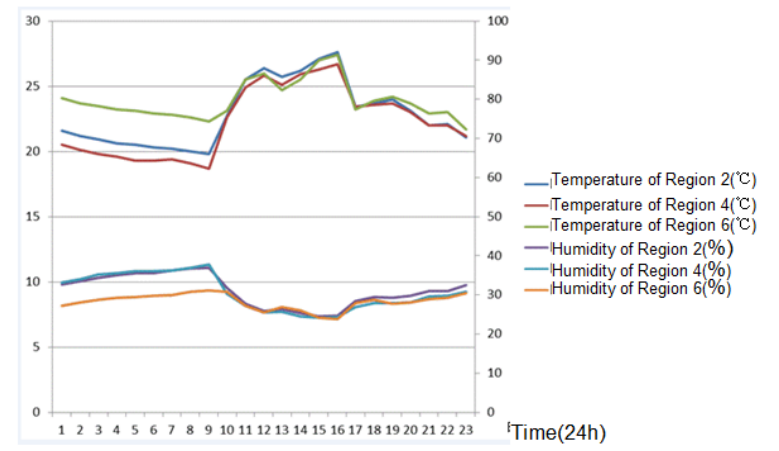

Figure 5. Temperature and moisture distribution of region 2, 4 and 6 during a typical day

\section{Acknowledgment}

This work was financially supported by the Anhui Provincial Natural Science Foundation (No. 1808085QE164, 1608085QE108), the Natural Science Research Project of Anhui Provincial Education Department (No. KJ2017A488, KJ2016SD14), the Science and Technology Major Projects of Anhui province (No. 16030801118) and the 13th Five-Year
Plan Key Project of Department of Science of China (No. 2017YFC0702600).

\section{References}

1. Li B, Yao R. Urbanization and its impact on building energy consumption and efficiency in China. Renewable Energy, 2009, 34(9):1994-1998.

2. Yang J, Zhou B, Jin M, et al. A novel complex air supply model for indoor air quality control via the occupant micro-environment demand ventilation. Chaos Solitons \& Fractals, 2016, 89:474-484.

3. Tao H, Fan $\mathrm{Y}$, Li X, et al. Investigation of formaldehyde and TVOC in underground malls in Xi'an, China: Concentrations, sources, and affecting factors. Building \& Environment, 2015, 85: 85-93.

4. An J Y, Kim S, Kim H J. Formaldehyde and TVOC emission behavior of laminate flooring by structure of laminate flooring and heating condition. Journal of Hazardous Materials, 2011, 187(1-3): 44-51.

5. Bohm M, Salem M Z, Srba J. Formaldehyde emission monitoring from a variety of solid wood, plywood, blockboard and flooring products manufactured for building and furnishing materials.[J]. Journal of Hazardous Materials, 2012, 221-222(4): 68-79.

6. Kim S, Kim J A, Kim H J, et al. Determination of formaldehyde and TVOC emission factor from wood-based composites by small chamber method. Polymer Testing, 2006, 25(5): 605-614.

7. Chi C, Chen W, Guo M, et al. Law and features of TVOC and formaldehyde pollution in urban indoor air. Atmospheric Environment, 2016, 132: 85-90.

8. Ding J, Huang H, Wang ZL. Analysis and research on air flow pattern of dry fan coil units and dedicated outdoor air system. Building Energy \& Environment, 2016, 35(5): 12-15. (in Chinese) 